\title{
One pedigree we all may have come from - 1 cosolatat did Adam and Eve have the chromosome 2 fusion?
}

Paweł Stankiewicz(1)

\begin{abstract}
Background: In contrast to Great Apes, who have 48 chromosomes, modern humans and likely Neandertals and Denisovans have and had, respectively, 46 chromosomes. The reduction in chromosome number was caused by the head-to-head fusion of two ancestral chromosomes to form human chromosome 2 (HSA2) and may have contributed to the reproductive barrier with Great Apes.
\end{abstract}

Results: Next generation sequencing and molecular clock analyses estimated that this fusion arose prior to our last common ancestor with Neandertal and Denisovan hominins $~ 0.74-4.5$ million years ago.

Hypotheses: I propose that, unlike recurrent Robertsonian translocations in humans, the HSA2 fusion was a single nonrecurrent event that spread through a small polygamous clan population bottleneck. Its heterozygous to homozygous conversion, fixation, and accumulation in the succeeding populations was likely facilitated by an evolutionary advantage through the genomic loss rather than deregulation of expression of the gene(s) flanking the HSA2 fusion site at 2 q13.

Conclusions: The origin of HSA2 might have been a critical evolutionary event influencing higher cognitive functions in various early subspecies of hominins. Next generation sequencing of Homo heidelbergensis and Homo erectus genomes and complete reconstruction of DNA sequence of the orthologous subtelomeric chromosomes in Great Apes should enable more precise timing of HSA2 formation and better understanding of its evolutionary consequences.

Keywords: Chromosomal fusion, Genomic rearrangements, Homozygosity, Human evolution, Gene loss, Evolutionary advantage

\section{Background}

Approximately one dozen of microscopically visible chromosomal aberrations, multiple subtelomeric heterochromatin expansions, and hundreds of submicroscopic structural variants involving both coding and non-coding sequences distinguish human and Great Ape genomes [1, $2]$. Among these numerous rearrangements, there are only two evolutionary chromosome translocations, $t(4 ; 19)$ in Gorilla gorilla [3-7] and head-to-head fusion forming human chromosome 2 (HSA2) [4, 8-10]. The latter reduced the number of chromosomes from 48 in Great Apes to 46 in humans.

Correspondence: pawels@bcm.edu

Department of Molecular and Human Genetics, Baylor College of Medicine, One Baylor Plaza, Rm ABBR-R809, Houston, TX 77030, USA

\section{Mechanism of HSA2 formation}

The HSA2 fusion site was first mapped using FISH within the telomeric repetitive sequences corresponding to the short arms of orthologous chimpanzee chromosomes PTR12 and PTR13 [11, 12]. Fan et al. analyzed the lowcopy repeat (LCR)-rich complex genomic structure and gene content of the $\sim 600 \mathrm{~kb}$ region surrounding the fusion site at $2 \mathrm{q} 13$ and mapped the chromosome junction within degenerate telomeric arrays in an intron of the non-coding DDX11L2 (DEAD/H-box helicase 11 like 2) transcript [13, 14]. Of note, the fusion site is resistant to PCR amplification and cloning. Genome-wide comparisons of recent chimpanzee and human LCRs revealed a $40 \mathrm{~kb}$ genomic fragment that map to four regions in the human genome, but is represented 400 times ('hyperexpansion') within the chimpanzee genome [15]. It was proposed that 
amplification of this interval occurred prior to HSA2 fusion and LCRs located close to the ancestral fusion sites might have facilitated the rearrangement between the closely flanking telomeric repeats of the two ancestral chromosomes. More recently, Ventura et al. [16] proposed a molecular-evolutionary model in which an ancestral human chimpanzee pericentric inversion and HSA2 fusion both predisposed and protected the chimpanzee and human genomes, respectively, to the formation of subtelomeric heterochromatin. Importantly, chromosome alignments, including positions of the active and vestigial [17] centromeres, as well as the current genome assemblies of HSA2, PTR12, and PTR13 chromosomes indicate that a few megabases of mostly repetitive satellite-rich subtelomeric DNA have been lost on both ancestral chromosomes (referred to as IIp and IIq) during the formation of HSA2 (Fig. 1).

\section{Time of HSA2 origin}

Computational genomic comparisons of AT to GC (weakto-strong) substitutions between the human and chimpanzee genomes using rhesus macaque as a reference allowed estimation of the fusion date at 0.74 million years ago (Mya) with a $95 \%$ confidence interval 0-2.81 Mya [18]. In support of this notion, using next generation sequencing (NGS) with a high-coverage (30x), Meyer et al. [19] have reconstructed a genome of a Denisovan, an extinct relative of Neandertals. They identified the HSA2 junction and concluded that Denisovans (and presumably Neandertals) shared the fused chromosome 2 with modern humans. Corroboratively, Ventura et al. [16] estimated that HSA2 fusion must have occurred early ( $>4$ Mya) during evolution, and most recently, Miga [20] analyzed satellite DNA in the HSA2 pseudocentromere at 2q21.2 [17] and calculated HSA2 fusion at $~ 3.5$ Mya (with a range of $\sim 2.5-4.5$ Mya).

\section{Hypotheses}

\section{Formation of HSA2 was a nonrecurrent rearrangement} event

(1) Given the high structural complexity of the genomic region flanking the HSA2 fusion site on chromosome $2 q 13$ and the fact that no HSA2 junction polymorphisms have been identified in modern humans, it is very unlikely that HSA2 fusion was a recurrent genomic rearrangement. I propose that HSA2 arose only once likely in one early modern human male and was subsequently transmitted and accumulated as a heterozygous event, converted to the homozygous state due to inbreeding in a small "bottleneck" polygamous clan (Fig. 2), and spread in the succeeding populations.

\section{Evolutionary advantage due to the genomic loss}

(2) The most comprehensive comparative analyses of the human and chimpanzee transcriptomes of 21,000 protein-

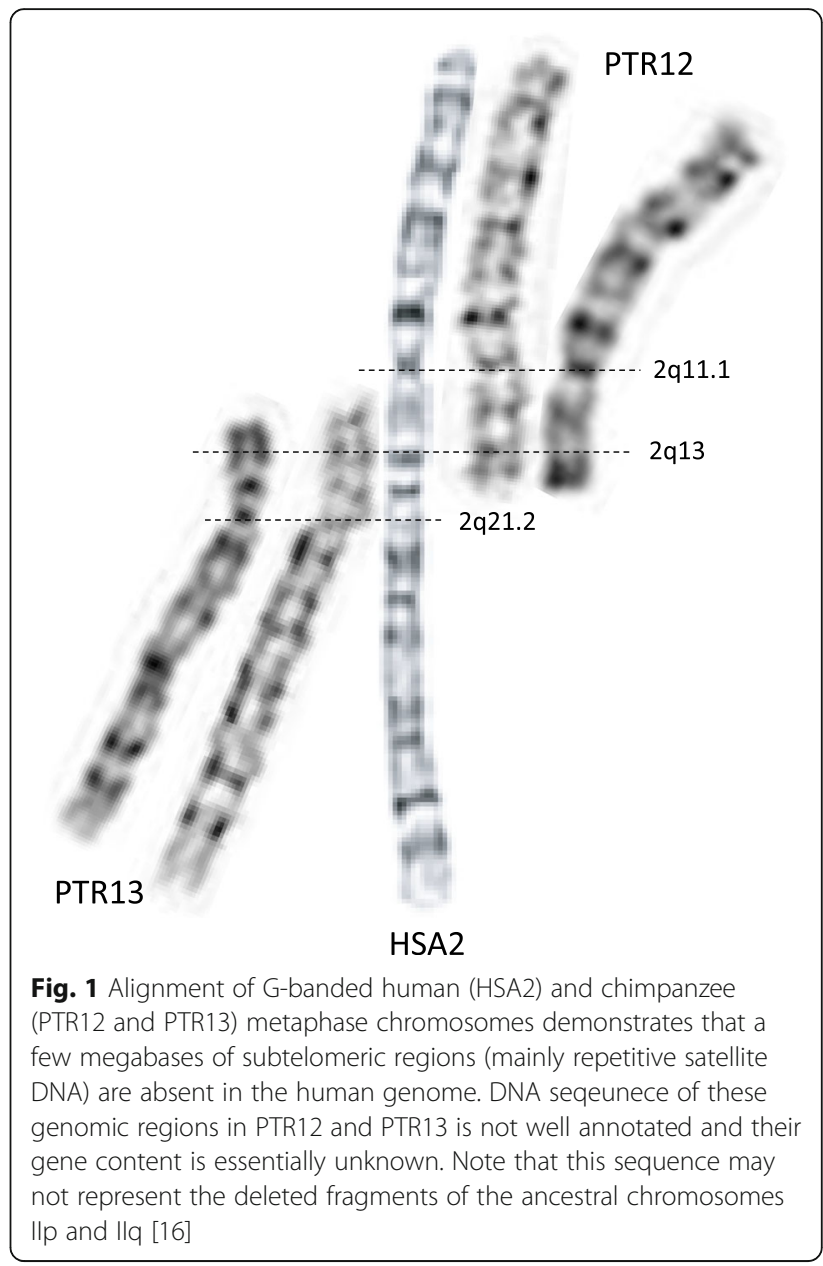

coding genes active in brain, heart, liver, kidney, and testis revealed that the patterns of tissue-specific gene expression and gene sequences are markedly similar [21]. I hypothesize that heterozygous and homozygous genomic loss of the putative gene(s) embedded in the repetitive subtelomeric sequences might have played a more important evolutionary role than deregulation of gene expression and/or a change of function of the genes flanking the HSA2 fusion site.

\section{Discussion}

\section{Recurrent chromosomal translocations}

Robertsonian translocations (ROBs), resulting from meiotic fusion of two acrocentric chromosomes (13-15, 21, or 22), occur in approximately one in every 1000 newborns. Although most ROB carriers are healthy, they are at increased risk of infertility and spontaneous abortions due to transmission of the unbalanced gametes [22]. ROBs are formed likely due to nonallelic homologous recombination (NAHR) between long stretches of highly similar repetitive satellite DNA sequences in the short arms of acrocentric chromosomes. Numerous examples 


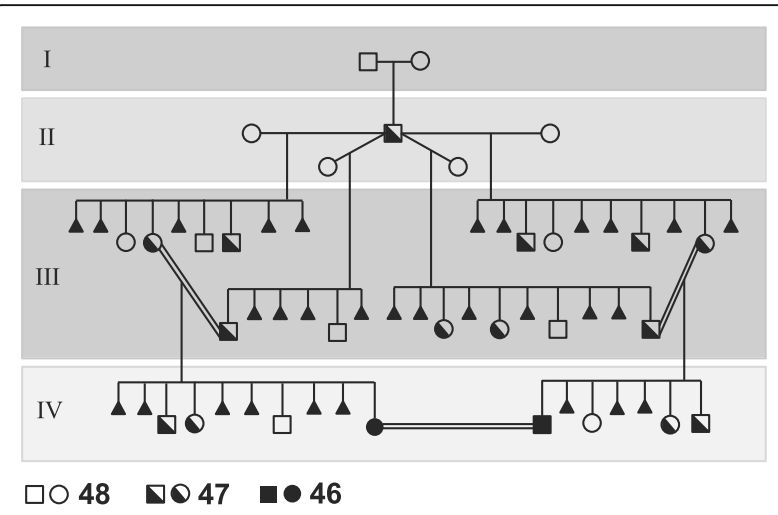

Fig. 2 A suggested gorilla-like [46] polygamous pedigree of a putative early modern human clan in which HSA2 was transmitted, implemented, and its heterozygous status converted to homozygous. A male carrier of a de novo heterozygous HSA2 (half filled square, Ind generation), had multiple children (Illrd generation) with a few female partners. Analogous to carriers of Robertsonian translocations, he is expected to have had healthy progeny with balanced 48 (blank square/circle) and 47 (half filled square/circle) chromosomes in addition to multiple miscarriages due to chromosomal imbalances (filled triangles). Note that the unions between individuals with 47 chromosomes heterozygous for HSA2 likely produced healthy children with balanced 48 and 47 chromosomes as well as heathy subjects with 46 chromosomes (homozygous for HSA2, IVth generation). The latter individuals are expected to have had an unaffected fecundity when inbreeding with carriers of balanced 46 chromosomes homozygous for HSA2. The evolutionary advantage might have resulted from an enhanced fertility e.g. due to testis-expressed DDX11L2. Alternatively, assortative mating between individuals with higher cognitive functions due to genomic loss (heterozygous or homozygous) of gene(s) important for brain development or function might have facilitated the successful spreading of HSA2

of various $\mathrm{ROB}$ fusion sites have been documented in the literature [23-25].

To date, only a few recurrent non-Robertsonian constitutional translocations have been described in humans. The most frequent $\mathrm{t}(11 ; 22)(\mathrm{q} 23 ; \mathrm{q} 11.2)$ results from a rearrangement between palindromic AT-rich repeats (PATRRs) (cruciform structures) [26, 27]. PATRRs were also found to mediate other recurrent constitutional translocations: $\mathrm{t}(17 ; 22)(\mathrm{q} 11.2 ; \mathrm{q} 11.2) \quad$ [28], $\mathrm{t}(4 ; 22)(\mathrm{q} 35.1 ; \mathrm{q} 11.2)$ [29], $\mathrm{t}(8 ; 22)(\mathrm{q} 24.13 ; \mathrm{q} 11.21)$ [30], and $\mathrm{t}(3 ; 8)$ (p14.2; 24.1 [31]. In addition, NAHR between inter-chromosomal LCRs (segmental duplications) was shown to result in recurrent constitutional translocations: $\mathrm{t}(4 ; 8)(\mathrm{p} 16.2 ; \mathrm{p} 23.1), \mathrm{t}(4 ; 11)(\mathrm{p} 16.2 ; \mathrm{p} 15.4)$, and $\mathrm{t}(8 ; 12)(\mathrm{p} 23.1 ; \mathrm{p} 13.31)$ [32, 33]. Similarly to ROBs, various recombination sites have been found in the NAHR-mediating LCRs.

Interestingly, breakpoints of the well-known human recurrent pericentric inversion inv(2)(p11.2q13) have been mapped $\sim 3 \mathrm{Mb}$ proximal to the HSA2 fusion site [34, 35]. The less frequent fragile site (FRA2B) at 2q13, which has not been fine mapped thus far, may have an impact on the reuse of $\operatorname{inv}(2)(\mathrm{p} 11.2 \mathrm{q} 13)$ and might have influenced the formation of the HSA2 fusion [36].

\section{Homozygosity for constitutional chromosomal aberrations}

Very rarely, chromosome aberrations are found in a homozygous state [37, 38]. Thus far, only 13 families with Robertsonian translocation present in a homozygous state (44 chromosomes) have been reported [39-51]. Recently, Song et al. [51] described a healthy 44,XY,der(14;15)(q10;q10),der(14;15)(q10;q10) male with no apparent defects in spermatogenesis and proposed that long term isolation of a group of individuals homozygous for a particular Robertsonian translocation chromosome could theoretically lead to the establishment of a new human subspecies with a full genetic complement in 44 chromosomes. However, to date, no such phenomenon has been reported for modern humans. In contrast to current monogamous social structure, early modern humans are thought to have lived in poly-gamous mating systems, similar to those typical for gorilla [52]. This has likely facilitated HSA2 spreading and its conversion from heterozygous to homozygous state (Fig. 2).

\section{Evolutionary advantage}

Out of the HSA2 fusion site directly flanking genes, $D D X 11 L 2$ expression is restricted to testis, RPL23AP7 and $C B W D 2$ are expressed in the brain, and WASH2P, $F A M 138 B$, and $R A B L 2 A$ have expression in the brain and testis higher than in other organs [53, 54]. Transcription profile change of some of these genes in the brain and/or testis might have resulted, respectively, in an improved cognitive functions and/or enhanced fecundity in individuals with heterozygous and homozygous HSA2. Alternatively, given the size of the genomic material absent on HSA2 when compared with Great Apes (Fig. 1), I propose that evolution of these early humans might have been driven primarily by loss of gene(s) in the most subtelomeric regions of the ancestral chromosomes IIp and IIq. Unfortunately, gene content in these genomic regions in Great Apes is currently unknown. Gene loss and pseudogenization have been shown to be pervasive engines of genetic variation during primate speciation $[55,56]$. Interestingly, compared to non-human primates, the human genome has had the fewest number of gene losses $[57,58]$.

\section{Conclusions}

The formation of HSA2 may have been a critical evolutionary event influencing e.g. higher cognitive functions, upright posture, endurance running, or improved thermoregulation by an enhanced sweating capacity in various subspecies and populations of hominins. Next generation sequencing of Homo heidelbergensis and Homo erectus genomes is technically challenging due to genomic DNA 
degradation and chemical modifications, but eventually may enable more precise timing of HSA2 origin. Moreover, complete DNA sequence reconstruction of the Great Ape orthologous subtelomeric chromosomes will help to better understand its evolutionary consequences. The multiversus single-origin hypotheses can be tested by analyzing the HSA2 fusion junction in various modern human populations. Detailed studies of the genetic processes leading to brain enlargement [59] can open new perspectives for better understanding the complex and unique relationships among molecular genetics and high human mental capabilities, including social life and development of culture.

\section{Abbreviations}

HSA2: Human chromosome 2; LCR: Low-copy repeat; Mya: Million years ago; NAHR: Nonallelic homologous recombination; NGS: Next generation sequencing; PATRR: Palindrome AT-rich repeat; PTR: Chimpanzee chromosome; ROB: Robertsonian translocation

\section{Acknowledgements}

I thank Drs. M. Gajecka, J.R. Lupski, T. Majewski, A. Patel, J. Rogers, J. Sikela, and G. Velagaleti for helpful discussion and K. Pham for technical assistance. We are grateful to Drs. P. Riger, M.E. Tocidlowski, and J. Flanagan from Houston Zoo for providing peripheral blood from the chimp Chaos.

\section{Funding}

Not applicable

Availability of data and material

Not applicable

\section{Competing interests}

The author declares that they have no competing interests.

\section{Consent for publication}

Not applicable

\section{Ethics approval and consent to participate}

Blood draw from a chimpanzee Chaos and G-banded karyotype analysis was approved by the Houston Zoo Review Committee.

Received: 18 August 2016 Accepted: 16 September 2016

Published online: 26 September 2016

\section{References}

1. Kehrer-Sawatzki H, Cooper DN. Molecular mechanisms of chromosomal rearrangement during primate evolution. Chromosome Res. 2008;16:41-56.

2. Wall JD. Great ape genomics. ILAR J. 2013;54:82-90.

3. Dutrillaux B, Rethore MO, Prieur M, Lejeune J. Analysis of the structure of chromatids of Gorilla gorilla. Comparison with Homo sapiens and Pan troglodytes. Humangenetik. 1973;20:343-54.

4. Yunis JJ, Prakash O. The origin of man: a chromosomal pictorial legacy. Science. 1982;215:1525-30.

5. Stanyon R, Wienberg J, Romagno D, Bigoni F, Jauch A, Cremer T. Molecular and classical cytogenetic analyses demonstrate an apomorphic reciprocal chromosomal translocation in Gorilla gorilla. Am J Phys Anthropol. 1992;88:245-50.

6. Kumar S, Hedges SB. A molecular timescale for vertebrate evolution. Nature. 1998:392:917-20

7. Stankiewicz P, Park SS, Inoue K, Lupski JR. The evolutionary chromosome translocation 4;19 in Gorilla gorilla is associated with microduplication of the chromosome fragment syntenic to sequences surrounding the human proximal CMT1A-REP. Genome Res. 2001;11:1205-10.

8. Turleau C, de Grouchy J, Klein M. Chromosomal phylogeny of man and the anthropomorphic primates. (Pan troglodytes, Gorilla gorilla, Pongo pygmaeus). Attempt at reconstitution of the karyotype of the common ancestor. Ann Genet. 1972;15:225-40.
9. Dutrillaux B. Chromosomal evolution in primates: Tentative phylogeny from Microcebus murinus (Prosimian) to man. Hum Genet. 1979;48:251-314.

10. Wienberg J, Jauch A, Lüdecke HJ, Senger G, Horsthemke B, Claussen U, et al. The origin of human chromosome 2 analyzed by comparative chromosome mapping with a DNA microlibrary. Chromosome Res. 1994;2:405-10.

11. IJdo JW, Baldini A, Ward DC, Reeders ST, Wells RA. Origin of human chromosome 2: an ancestral telomere-telomere fusion. Proc Natl Acad Sci USA. 1991;88:9051-5.

12. Kasai F, Takahashi E, Koyama K, Terao K, Suto Y, Tokunaga K, et al. Comparative FISH mapping of the ancestral fusion point of human chromosome 2. Chromosome Res. 2000;8:727-35.

13. Fan Y, Linardopoulou E, Friedman C, Williams E, Trask BJ. Genomic structure and evolution of the ancestral chromosome fusion site in 2q13-2q14.1 and paralogous regions on other human chromosomes. Genome Res. 2002;12:1651-62.

14. Fan Y, Newman T, Linardopoulou E, Trask BJ. Gene content and function of the ancestral chromosome fusion site in human chromosome 2q13-2q14.1 and paralogous regions. Genome Res. 2002;12:1663-72.

15. Cheng Z, Ventura M, She X, Khaitovich P, Graves T, Osoegawa K, et al. A genome-wide comparison of recent chimpanzee and human segmental duplications. Nature. 2005;437:88-93.

16. Ventura M, Catacchio CR, Sajjadian S, Vives L, Sudmant PH, Marques-Bonet $T$, et al. The evolution of African great ape subtelomeric heterochromatin and the fusion of human chromosome 2. Genome Res. 2012;22:1036-49.

17. Avarello R, Pedicini A, Caiulo A, Zuffardi O, Fraccaro M. Evidence for an ancestral alphoid domain on the long arm of human chromosome 2. Hum Genet. 1992;89:247-9.

18. Dreszer TR, Wall GD, Haussler D, Pollard KS. Biased clustered substitutions in the human genome: the footprints of male-driven biased gene conversion. Genome Res. 2007;17:1420-30.

19. Meyer M, Kircher M, Gansauge MT, Li H, Racimo F, Mallick S, et al. A high-coverage genome sequence from an archaic Denisovan individual. Science. 2012;338:222-6.

20. Miga KH. Chromosome-Specific Centromere Sequences Provide an Estimate of the Ancestral Chromosome 2 Fusion Event in Hominin Genomes. J Hered. 2016 doi: 10.1093/jhered/esw039

21. Khaitovich P, Hellmann I, Enard W, Nowick K, Leinweber M, Franz H, et al. Parallel patterns of evolution in the genomes and transcriptomes of humans and chimpanzees. Science. 2005;309:1850-4.

22. McKinlay Gardner RJ, Sutherland GR, Shaffer LG. Robertsonian translocations. In: Chromosome abnormalities and genetic counseling. New York: Oxford University Press; 2012. p. 140-154.

23. Jarmuz M, Glotzbach CD, Bailey KA, Bandyopadhyay R, Shaffer LG. The Evolution of satellite III DNA subfamilies among primates. Am J Hum Genet. 2007:80:495-501.

24. Jarmuz-Szymczak M, Janiszewska J, Szyfter K, Shaffer LG. Narrowing the localization of the region breakpoint in most frequent Robertsonian translocations. Chromosome Res. 2014:22:517-32.

25. Bint SM, Scriven PN, Ogilvie CM. Successful PGD cycles for mosaic Robertsonian translocation carriers provide insights into the mechanism of formation of the derivative chromosomes. Am J Med Genet A. 2013;161A:566-71.

26. Kurahashi H, Shaikh TH, Hu P, Roe BA, Emanuel BS, Budarf ML. Regions of genomic instability on $22 \mathrm{q} 11$ and $11 \mathrm{q} 23$ as the etiology for the recurrent constitutional t(11:22). Hum Mol Genet. 2000:9:1665-70.

27. Edelmann L, Spiteri E, Koren K, Pulijaal V, Bialer MG, Shanske A, et al. AT-rich palindromes mediate the consitutional $\mathrm{t}(11 ; 22)$ translocation. Am J Hum Genet. 2001;68:1-13.

28. Kurahashi H, Shaikh TH, Takata M, Toda T, Emanuel BS. The constitutional $\mathrm{t}(17 ; 22)$ : another translocation mediated by palindromic AT-rich repeats. Am J Hum Genet. 2003;72:733-8.

29. Nimmakayalu MA, Gotter AL, Shaikh TH, Emanuel BS. A novel sequencebased approach to localize translocation breakpoints identifies the molecular basis of a t(4;22). Hum Mol Genet. 2003:12:2817-25.

30. Sheridan MB, Kato T, Haldeman-Englert C, Jalali GR, Milunsky JM, Zou Y, et al. A palindrome-mediated recurrent translocation with 3:1 meiotic nondisjunction: the $\mathrm{t}(8 ; 22)(\mathrm{q} 24.13 ; \mathrm{q} 11.21)$. Am J Hum Genet. 2009;87: 209-18.

31. Kato T, Franconi CP, Sheridan MB, Hacker AM, Inagakai H, Glover TW, et al. Analysis of the $t(3 ; 8)$ of hereditary renal cell carcinoma: a palindrome-mediated translocation. Cancer Genet. 2014;207:133-40. 
32. Giglio S, Calvari V, Gregato G, Gimelli G, Camanini S, Giorda R, et al. Heterozygous submicroscopic inversions involving olfactory receptorgene clusters mediate the recurrent $t(4 ; 8)(p 16 ; p 23)$ translocation. Am J Hum Genet. 2002;71:276-85.

33. Ou Z, Stankiewicz P, Xia Z, Breman AM, Dawson B, Wiszniewska J, et al. Observation and prediction of recurrent human translocations mediated by NAHR between nonhomologous chromosomes. Genome Res. 2011;21:33-46.

34. Schmidt S, Claussen U, Liehr T, Weise A. Evolution versus constitution: differences in chromosomal inversion. Hum Genet. 2005;117:213-9.

35. Fickelscher I, Liehr T, Watts K, Bryant V, Barber JC, Heidemann S, et al. The variant $\operatorname{inv}(2)$ (p11.2q13) is a genuinely recurrent rearrangement but displays some breakpoint heterogeneity. Am J Hum Genet. 2007:81:847-56.

36. Mrasek K, Schoder C, Teichmann AC, Behr K, Franze B, Wilhelm K, et al. Global screening and extended nomenclature for 230 aphidicolin-inducible fragile sites, including 61 yet unreported ones. Int J Oncol. 2010;36:929-40.

37. O'Neill ID. Homozygosity for constitutional chromosomal rearrangements: a systematic review with reference to origin, ascertainment and phenotype. J Hum Genet. 2010;55:559-64.

38. Bi W, Probst FJ, Wiszniewska J, Plunkett K, Roney EK, Carter BS, et al. Co-occurrence of recurrent duplications of the DiGeorge syndrome region on both chromosome 22 homologues due to inherited and de novo events. J Med Genet. 2012;49:681-8.

39. Neu RL, Valentine FA, Gardner LI. Segregation of a t(14q22q) chromosome in a large kindred. Clin Genet. 1975;8:30-6.

40. Rockman-Greenberg C, Ray M, Evans JA, Canning N, Hamerton JL. Homozygous Robertsonian translocations in a fetus with 44 chromosomes. Hum Genet. 1982;61:181-4.

41. Martinez-Castro P, Ramos MC, Rey JA, Benitez J, Sanchez CA. Homozygosity for a Robertsonian translocation (13q14q) in three offspring of heterozygous parents. Cytogenet Cell Genet. 1984;38:310-2.

42. Morgan R, Bixenman H, Hecht F. Human chromosome variation with two Robertsonian translocations. Hum Genet. 1985;69:178-80.

43. Eklund A, Simola KO, Ryynänen M. Translocation $t(13 ; 14)$ in nine generations with a case of translocation homozygosity. Clin Genet. 1988;33:83-6.

44. Dallapiccola B, Ferranti G, Altissimi D, Colloridi F, Paesano R. First-trimester prenatal diagnosis of homozygous (14;21) translocation in a fetus with 44 chromosomes. Prenat Diagn. 1989;9:555-8.

45. Rajangam S, Michaelis RC, Velagaleti GV, Lincoln S, Hegde S, Lewin S, et al. Down syndrome with biparental inheritance of der(14q21q) and maternally derived trisomy 21: confirmation by fluorescent in situ hybridization and microsatellite polymorphism analysis. Am J Med Genet. 1997;70:43-7.

46. Sensi A, Cavani S, Villa N, Pomponi MG, Fogli A, Gualandi F, et al. Nonhomologous Robertsonian translocations (NHRTs) and uniparental disomy (UPD) risk: an Italian multicentric prenatal survey. Prenat Diagn. 2004;24:647-52

47. Omrani MD, Gargari SS. Uniparental disomy resulting from heterozygous Robertsonian translocation (13q14q) in both parents. J Res Med Sci. 2007;12:100-3.

48. Abdalla EM, Kholeif SF, Elshaffie RM. Homozygosity or a Robertsonian translocation $(13 q ; 14 q)$ in an otherwise healthy $44, X Y$ man with a history of repeated fetal losses. Lab Medicine. 2013;44:254-7.

49. Wang B, Xia Y, Song J, Wang W, Tang Y. Case Report: Potential speciation in humans involving robertsonian translocations. Biomed Res. 2013;24:171-4.

50. Miryounesi M, Diantpour M, Motevaseli E, Ghafouri-Fard S. Homozygosity for a Robertsonian Translocation (13q;14q) in a Phenotypically Normal 44, XX Female with a History of Recurrent Abortion and a Normal Pregnancy Outcome. J Reprod Infertil. 2016;17:184-7.

51. Song J, Li X, Sun L, Xu S, Liu N, Yao Y, et al. A family with Robertsonian translocation: a potential mechanism of speciation in humans. Mol Cytogenet. 2016;9:48.

52. Nelson E, Rolian C, Cashmore L, Shultz S. Digit ratios predict polygyny in early apes, Ardipithecus, Neanderthals and early modern humans but not in Australopithecus. Proc Biol Sci. 2011;278:1556-63.

53. BioGPS gene annotation portal, http://biogps.org/\#goto=welcome.

54. GTExPortal, http://www.gtexportal.org/home/. Accessed on Sept 22, 2016.

55. Olson MV. When less is more: gene loss as an engine of evolutionary change. Am J Hum Genet. 1999;64:18-23.

56. Hahn MW, Demuth JP, Han SG. Accelerated rate of gene gain and loss in primates. Genetics. 2007;177:1941-9.
57. Demuth JP, De Bie T, Stajich JE, Cristianini N, Hahn MW. The evolution of mammalian gene families. PLoS One. 2006:1:e85.

58. Wang X, Grus WE, Zhang J. Gene losses during human origins. PLoS Biol. 2006:4:e52.

59. Dumas LJ, O'Bleness MS, Davis JM, Dickens CM, Anderson N, Keeney JG, et al. DUF1220 domain copy number implicated in human brain-size pathology and evolution. Am J Hum Genet. 2012;91:444-54.

\section{Submit your next manuscript to BioMed Central and we will help you at every step:}

- We accept pre-submission inquiries

- Our selector tool helps you to find the most relevant journal

- We provide round the clock customer support

- Convenient online submission

- Thorough peer review

- Inclusion in PubMed and all major indexing services

- Maximum visibility for your research

Submit your manuscript at www.biomedcentral.com/submit
C Biomed Central 